\title{
Caracterização e problemas atuais do barranquenho: contribuiçóes para uma política de revitalização
}

\section{Features and current problems of the Barranquenho: contributions to a revitalisation policy}

\author{
María Victoria Navas Sánchez-Élez \\ Universidad Complutense de Madrid (España) / Centro de Linguistica da Universidade de Lisboa \\ (Portugal) \\ mvnavas@filol.ucm.es
}

Maria Filomena Gonçalves

Universidade de Évora-ECS-DLL / Centro Interdisciplinar de História, Culturas e Sociedades da Universidade de Évora (Portugal)

mfg@uevora.pt

Recibido: 20/05/2019

Aceptado: 18/05/2020

\section{Resumo}

Neste artigo analisa-se a situaçáo atual - resultado do contacto multissecular entre o português e o espanhol - de uma variedade linguística mista falada numa vila portuguesa do Alentejo: o barranquenho. O objetivo deste trabalho é propor uma revisão do estatuto e da tipologia até agora atribuídos a esta variedade - dialeto, fala fronteiriça ou raiana - que, em virtude das suas características, deveria ser tratada como uma língua de contacto, minoritária, ameaçada e em perigo de extinção. A metodologia utilizada consiste em compulsar várias fontes relativas ao barranquenho, assim como dados recolhidos em inquéritos realizados em Barrancos, de maneira a averiguar-se a perceção que, de fora da comunidade, se tem do barranquenho, mas também a consciência linguística da própria comunidade sobre a sua língua. Com este estudo pretende-se contribuir para o reconhecimento do barranquenho como língua lato sensu e mostrar a necessidade de uma política e planificação linguísticas que permita preservá-la das ameaças que sobre ela pairam.

\section{Palabras-chave}

Barranquenho; sociolinguística; política linguística; língua ameaçada; património cultural imaterial

\section{Sumário}

1. Apresentação. 2. A consciência linguística: a autoestima. 3. Preservaçấo linguística de uma língua ameaçada. 3.1. Um pouco de história. 3.2. Classificar para preservar. 4 . Notas finais.

\begin{abstract}
In this article, we analyse the current situation-a centuries-old result of contacts between Portuguese and Spanish — of a hybrid linguistic variant spoken in the Alentejo region, i.e., Barranquenho. Additionally, we propose a revision of the status and typology that up until now have been attributed to this variantalso referred to as dialect, border language, or raiana ("border line" or "strip" language) — that, due to its characteristics, should be considered as a contact language, a minority language, an endangered language, and a language on the brink of extinction. As for our methodological approach, we compiled various sources on Barranquenho, as well as data gathered from research and surveys conducted in Barrancos aimed at ascertaining the perception that people living outside the community of its speakers' have of Barranquenho. Furthermore, we have also examined the linguistic awareness that speakers of Barranquenho have of their own language. Our research is thus a contribution to studies aimed at recognising Barranquenho as a lato sensu language while calling upon the need for a linguistic policy and planning aimed at preserving it from extinction.
\end{abstract}

\section{Keywords}

Barranquenho; sociolinguistics; linguistic policy; endangered language; intangible cultural heritage

\section{Contents}

1. Introduction. 2. Linguistic conscience: self-esteem. 3. Preserving a threatened language. 3.1. A little bit of history. 3.2. Classify to preserve. 4. Final remarks. 


\section{Apresentação}

$\triangle$ IDEIa generalizada de que Portugal e os países de Língua Portuguesa (veja-se Io caso do Brasil) são basicamente monolingues tem-se alterado ao longo dos anos e, atualmente, essa visão faz parte do passado, conforme demonstra, no caso de Portugal, o reconhecimento do estatuto de língua cooficial ao mirandês ${ }^{1}$ em 1998. Mas, na verdade, a promoção da diversidade linguística e das minorias linguísticas, reduz-se frequentemente a manifestaçóes pontuais de tipo cultural, como feiras, exposiçóes e outras, ao passo que a promoção das línguas estatais, por assim dizer, se baseia em métodos que reforçam e consolidam o seu estatuto, como acontece com o português, o espanhol, o alemão, por exemplo. Contudo, desde a década de 80 do século passado, essas tendências têm vindo a ser contrariadas graças, por um lado, a iniciativas locais que têm permitido a integração de políticas eficazes e adequadas à realidade dos falantes bilingues e multilingues num mesmo panorama multicultural e, por outro, à crescente valorizaçáo da diversidade linguística por parte de organismos internacionais como a UNESCO, por exemplo, e, ainda, ao interesse dos investigadores pela documentaçáo, estudo e preservaçáo de variedades e línguas minoritárias e ameaçadas.

Entre os estudiosos das línguas fronteiriças peninsulares é bem conhecida a situação do barranquenho: língua mista (Navas 1992, 2011, 2014, 2015b, 2017a, 2017b, 2017c), produto contínuo do contacto, das variedades meridionais do português e do espanhol falado em Barrancos (Adragáo 1978; Navas 2000), vila que se situa no distrito alentejano de Beja, vizinho da província andaluza de Huelva, junto à confluência do norte desta com o sul da província de Badajoz. Súbditos do reino de Castela e Leão, amparados pela Ordem de Avis pelo menos desde o século xv, fixaram-se nestas terras de ninguém, por assim dizer, e propiciaram a criação de uma nova língua (Navas 2017a: 54-57), à qual, na esteira da obra pioneira de José Leite de Vasconcelos (1858-1941), se tem chamado "dialecto barranquenho" (Vasconcelos 1955). As origens de Barrancos, cujo topónimo reflete a orografia local e está atestado pelo menos desde 1527 (Vasconcelos 1939: 159), encontram-se no Castelo de Noudar (Coelho 1986), fortificação medieval que se situa a alguns quilómetros da localidade, e que, depois de várias vicissitudes históricas, acabaria por ser abandonada. Para se aquilatar a importância do fluxo contínuo de pessoas de um lado para o outro, neste espaço verdadeiramente hispano-português, bastará sublinhar que aqui não existiu uma fronteira política definitiva até 1894, e que o limite natural foi sempre o Ardila,

1. No seu artigo 2..$^{\circ}$, o Decreto $n^{\circ} 303 / V I I$ - Reconhecimento oficial de direitos linguísticos da comunidade mirandesa, II Série - número 29, 786, o Estado Português "reconhece o direito a cultivar e promover a língua mirandesa, enquanto património cultural, instrumento de comunicaçáo e de reforço da identidade da terra de Miranda". http://debates.parlamento.pt/catalogo/r3/dar/ s2a/07/04/028/1999-0109/786?pgs=786\&org=PLC [12/02/2018]. 
rio que, por ter pouco caudal, pode ser atravessado sem grande dificuldade. Fruto do repovoamento de base castelhana, cuja presença foi maioritária até ao século xx, e da afluência de população portuguesa, criou-se uma língua única que, devido a diversas causas (geográficas, políticas, sociais e económicas) se tem mantido ao longo do tempo.

Afastados dos centros de poder portugueses ${ }^{2}$, mas muito próximos da realidade económica, social e viária ${ }^{3}$ da vida espanhola, durante séculos os barranquenhos mantiveram, devido ao seu isolamento dos centros decisórios portugueses, e graças à proximidade com os vizinhos espanhóis, uma cultura híbrida, fechada sobre si própria face a Portugal, mas aberta a Espanha (Bastos \& Everard 1982).

Sem tradiçáo escrita, a língua barranquenha apresenta uma cultura que, devido à história da comunidade (Cosme 2001), em geral é de base espanhola, conforme se observa em cançóes, na literatura oral e tradicional (Navas 2017a; Quijada 2012), nos costumes, tradiçôes (Revez \& Cascalheira 2010), culinária, numa idiossincrasia muito particular. Tudo isto assenta na forte presença de forças vivas originárias de Espanha, em períodos recentes de sua história, o que levou a que a comunidade, em grande parte diglóssica, seja hoje trilingue em português, barranquenho e espanhol, no plano oral, sendo o barranquenho a língua dominante na maioria das situaçóes da vida doméstica e comunitária. A sua especificidade é reconhecida pelos próprios barranquenhos:

O barranquenho tem um cunho particular, uma identidade muito própria. Não diria que é independentista, mas, devido ao esquecimento a que foi votado, aprendeu a governar-se a ele próprio [...]. Até há pouco tempo, a administração portuguesa quase que não era tida, nem achada, aqui em Barrancos. [...] Estivemos esquecidos até ao 25 de Abril, que é quando se dá um salto qualitativo e, digamos assim, abrem-se as visões do Terreiro do Paço (Presidente da Câmara de Barrancos, em 1996, apud Franco 2005: 229).

Mas esta a referida peculiaridade é reconhecida pelos seus vizinhos portugueses, conforme mostra a afirmação de Cristiana Bastos e Pedro Everard (1982), num estudo antropológico que serve de orientação para conhecer o parecer das povoaçôes vizinhas:

Barrancos é diferente do resto; tem dialecto, autonomia, a sua gente considera-se barranquenha e chama portugueses e espanhóis aos visitantes, consoante vêm de Oeste ou de Leste (Notícias de Beja, Bastos \& Everard 1982: 14).

2. Em palavras de N. Franco (2005: 15), "Ao longo dos séculos, Portugal tratou Barrancos mais como enteada do que como filha".

3. Encinasola, povoação da província de Huelva, está a apenas $11 \mathrm{Km}$ de Barrancos, ao passo que a Amareleja, a vila alentejana mais próxima, fica a 27 , sendo necessário percorrer uma estrada estreita e perigosa. 
À luz do conhecimento atual sobre a consciência linguística relativa à língua barranquenha ${ }^{4}$, e a partir de diferentes óticas - na perspetiva antropológica e etnográfica, veja-se, por exemplo, o trabalho de N. Franco (2005) - alguns investigadores portugueses que, nos últimos anos, se têm dedicado ao estudo da história e cultura sublinham a sua independência em relação à língua estândar (o português):

Desde que exista uma autonomia sintáctica é possível considerar que estamos em presença de uma língua [...] [a sintaxe] é um factor decisivo para definir uma língua autónoma [...]; o barranquenho poderá vir a ser considerado, no futuro, também uma língua oficial minoritária (Martinho apud Franco 2005: 63).

Em frases recolhidas de barranquenhos, o autor, identifica certas estruturas sintáticas próprias da língua barranquenha, como seja a colocação proclítica do pronome, em "A bicha conforme le farejava se escondia debaixo de uma laja grande", "Me casei com a minha mulher", "Se faziam as morcelas, se deitava a sangue e se cozia a sangue"; construçôes com o verbo gostar, em "porque nos gustou, porque era assim clarinha", "onde comeu o pinhonate que tanto le gostaba"; ou a preferência pelo pretérito perfeito composto versus o pretérito perfeito, em "Não sei se tem ouvido falar", "Olha, que fizemos vinte e tal contos e agora em pouco mais de dois meses ou três os tenho gasto", frases a cavalo entre a língua portuguesa e a espanhola, entendendo, por isso, N. Franco (2005) - entre outros - que o barranquenho é uma língua específica, aparentada com as línguas románicas (português e espanhol), mas com autonomia própria.

Contudo, a peculiaridade barranquenha nem sempre é sentida pelos seus compatriotas de forma favorável, como indicam informaçôes de cariz antropológico recolhidas na vila (Bastos \& Everard 1982):

Os de Barrancos não são portugueses nem espanhóis: de dia falam uma língua e de noite outra, variam do dia para a noite (depoimento recolhido na Amareleja, segundo Bastos e Everard 1982: 14).

Em Barrancos sinto-me em Marrocos (opiniāo de Paulo Casimiro, recolhida em Bastos e Everard 1982: 114).

4. Em linha com estudos das áreas quer da sociolinguística quer do contacto linguístico, tal como exposto em Navas e Gonçalves (2018), tanto os traços linguísticos (sintáticos mas não só) como as peculiares características sociais do barranquenho, permitem hoje considerá-lo como uma língua lato sensu, fruto de um contacto multissecular numa comunidade mista. Falada numa região fronteiriça, é uma língua comunitária que assenta em variedades meridionais do português e do espanhol. De acordo com Navas e Gonçalves (2018), a literatura anterior refere o barranquenho como "dialeto", "falar fronteiriço" ou "variedade raiana". Contudo, em virtude das suas marcas estruturais e da situação sociolinguística da comunidade, o barranquenho funciona como uma língua materna na qual se enraiza a identidade local (Golovko 2003). 
Por outro lado, entre os dialetológos também não existe convergência de perspectivas, conforme sublinha N. Franco (2005: 63), ao apontar as posiçóes de Manuela Barros Ferreira ${ }^{5}$ e Manuel Alvar. Este último, com efeito, trata do barranquenho num pequeno capítulo (Alvar 1996: 259-262) do seu Manual, classificando-o primeiramente como "dialecto" para, após uma breve caracterização fonológica, morfossintática e lexical, se referir a ele como "língua mixta" que é

Resultado de un bilingüismo que viene actuando desde el siglo XVI y que hoy permite levantar varios estratos en la descripción funcional que poseemos, pues si hay rasgos castellanos que hablan del antiguo bilingüismo, otros, en su modernidad, nos hacen pensar en lenguas en contacto, cuyas características proceden de los dialectos españoles más próximos (extremeño y andaluz) (Alvar 1996: 261-262).

Concluindo depois o seguinte:

[...] podemos pensar en el nacimiento de una estructura mixta producto del bilingüismo: de una parte tradición y ciertas razones geográficas abonan por el carácter español del barranqueño, mientras que el portuguesismo resulta de otros motivos geográficos y de la "natural evolución del sentimiento patriótico y político, acompañada de la intervención del Gobierno Central". Se está llegando -si no se ha llegado ya- a un bilingüismo que necesariamente lastimará a una de las dos lenguas, con independencia de esos términos que se intercambian a ambos lados de la frontera, como resultado de las relaciones que en lingüística llamamos adstrato (Alvar 1996: 262).

Para se ilustrar a "estrutura mista" que caracteriza o barranquenho, e pondo de remissa a questão das tipologias das línguas mistas (Matras \& Bakker 2003; Bakker 2015, Meakens 2018), de entre os seus muitos traços distintivos salientem-se apenas alguns dos que refletem o contacto com o espanhol (Navas 2017a: passim): no plano fonológico, a aspiração e a elisão da sibilante em posição implosiva, a labiodental /v/

5. A propósito do reconhecimento do mirandês como língua cooficial, em declaração ao jornal Público (17 e 19 de setembro de 1998), a dialetóloga sublinhou que "possui [o mirandês] uma estrutura específica que evoluiu a partir do leonês, com uma forma própria e exterior às línguas ibéricas, e a sua fonologia exige uma ortografia diferente do português, o que não acontece com mais nenhum dialecto em Portugal", acrescentando que o barranquenho é "uma situação falada que utiliza a ortografia do português, não sendo, por isso, possível falar de uma língua, mas sim de um dialecto" (apud Franco 2005: 63). Ora, este último argumento não válido, visto que o barranquenho continua a ser uma língua ágrafa, sem qualquer representaçáo convencionada. Assim, o recurso à ortografia portuguesa em intentos de representação do barranquenho não pode ser um critério para invalidar a atribuição do estatuto de "língua" ao barranquenho. Embora este e o mirandês resultem de processos genéticos muito distintos - continuidade histórica de um romance medieval, no segundo, e contacto entre dois sistemas românicos aparentados, no primeiro -, a ausência de codificação gráfica própia não é critério que deva sobrepor-se às condiçóes sociolinguísticas da comunidade. 
realizada como bilabial ou, ainda, a perda das líquidas /r/ y /l/ em posição final; no plano morfossintático, o género de certas palavras coincide com o das correspondentes espanholas (la sá 'o sal', a sangue crua 'sangue cru'), o uso do pretérito perfeito composto (me tenho atado em vez de "atei"), a já mencionada colocação proclítica dos pronomes (a formiga le disse que sim). Seria extenso o rol de particularidades do barranquenho nos referidos níveis linguísticos, assim como no léxico e na fraseologia, âmbitos em que o contacto com o espanhol deixou marcas abundantes e evidentes (codo 'cotovelo', párpado 'pálpebra', tobilho 'tornozelo', mareos 'tonturas'), ainda cheias de vitalidade.

Além de M. Alvar, são vários os autores que, já no nosso século atual, explicam esta língua mista a partir de processos de aquisição inerentes ao bilinguismo (Clements 2009; Clements / Amaral \& Luís 2007, 2008; Clements / Amaral \& Luís 2011: 395-396), numa comunidade que, devido às condiçôes geográficas, históricas, culturais e sociais, é particularmente propícia a uma análise de tipo variacionista (Carvalho / Lucchesi 2016: 52), porquanto a distribuição social e estilística dos traços mais salientes é muito irregular (Navas 2017a), o que levanta problemas de várias ordens a qualquer processo de codificação e, em concreto, de criação de um sistema gráfico que retenha o essencial do sistema oral.

As mais recentes perspetivas aplicadas ao caso do barranquenho põem em relevo uma singularidade que, na verdade, chamara já a atenção de José Leite de Vasconcelos desde os finais do século XIX e os inícios do seguinte (Vasconcelos 1897, 1901, 1935, 1939). Língua singular no espaço românico europeu, possivelmente com vários centos de anos de vida, foi objeto de um "modesto" esboço do então já idoso Leite de Vasconcelos que, conhecedor do caráter incompleto do seu trabalho mas consciente da sua importância, aconselhou que se completasse com uma gramática e um vocabulário: "o barranquenho merece que se lhe dedique desvelada atenção, e não se deixe morrer sem que a sua gramática e léxico fiquem devidamente investigados" (Vasconcelos 1955: 31-32). Porém, a língua barranquenha não teve essa sorte até agora. No panorama das variedades das línguas peninsulares existem centenas de títulos, senão mesmo milhares, que recolhem as falas, de um extremo ao outro da Península Ibérica, com os seus respetivos vocabulários, gramáticas e literaturas (Navas 2017b). No caso do barranquenho - língua e cultura - a situação é, de facto, bem distinta porque apenas nos últimos dez anos se têm desencadeado iniciativas destinadas a incluí-lo no panorama atrás referido. Com efeito, os vários projetos lançados neste período - um deles levaria, em 2008, à classificação do barranquenho como Património Cultural Imaterial de Interesse Municipal (Navas 2013) - tendem a confluir numa política linguística contínua, de longo prazo, que, para preservar esta língua, inclua um processo de "normalização" ou "estandardização" (Metzeltin 2005, 2015), o que supõe não só a criação de um sistema de escrita ou convenção ortográfica ${ }^{6}$ (Correia 2017; Navas

6. Foi o que sucedeu com o mirandês, após reconhecimento dos seus direitos (Ferreira \& Raposo 1999). 
2015b; Navas \& Gonçalves 2018), o estudo da língua, a gramática e o léxico, mas também uma dinâmica programada e constante no seio da comunidade em torno à sua fala, medidas que desembocarão, naturalmente, no reconhecimento do estatuto de língua a nível local e, posteriormente, a nível nacional ${ }^{7}$, em consonância com o que aconteceu com o mirandês em $1998^{8}$, ainda que, por si só, como se vem observando no caso do mirandês, este reconhecimento não assegure, a longo prazo, nem a preservação nem a vitalidade de uma língua minoritária. Ao barranquenho aplicam-se, sem dúvida, os argumentos expendidos a propósito tanto da "sobrevivência das comunidades linguísticas em situação minoritária” (Lagares 2018: 152-156) como dos aspetos que permitem que uma língua "seja sustentável em seu contexto social concreto" (Lagares 2018: 155).

Este desafio - linguístico e "glotopolítico" (Lagares 2018) - requer muito empenho, quer por parte do poder local, quer por parte da comunidade e, igualmente, dos investigadores comprometidos com a "planificação linguística", desenhada e definida para a situação específica de Barrancos. Apesar da sua (ainda) atual vitalidade, as ameaças que pairam sobre os barranquenhos são reais, ainda que delas estes não tenham plena consciência, e poderão traduzir-se, num curto prazo, na total assimilação pelo português, a língua da administração, da escola, dos meios de comunicação e das terras vizinhas.

A urgência de medidas de política linguística (Correia 2019) encontra eco em estudos sobre a "diversidade linguística" levados a cabo por organismos da Uniáo Europeia como, por exemplo, em 1992, a Carta Europeia das Linguas Regionais e Minoritárias (European Charter for Regional and Minoritary Languages), documento que já consagrava os direitos de variedades e línguas, ressaltando o valor intrinsecamente cultural de manifestaçôes linguísticas inalienáveis da história e da identidade coletiva das comunidades humanas, direitos que, em 1996, ficaram plasmados na Declaração Universal dos Direitos Linguísticos aprovada pela UNESCO. Vem a propósito referir que, a despeito das recomendaçóes feitas em 2017 pelo Comité de Especialistas para as Línguas Minoritárias da Comissão Europeia, até hoje Portugal não assinou a referida Carta.

Ao barranquenho, língua singular no contexto peninsular e europeu, aplicam-se as disposiçóes consagradas em 1996 na Declaração Universal dos Direitos Linguísticos, cujo Título $1^{\circ}, \operatorname{Art}^{\circ} 9^{\circ}$ estabelece que esses direitos se aplicam a todas as línguas, sem

7. F. Fernández Rei (2014) coloca a possibilidade de esta, na esteira do mirandês, vir a ser a terceira língua de Portugal: "Arelamos que algún día o Parlamento luso recońeza o barranqueño como a terceira lingua de Portugal”. https://www.facebook.com/Prolinguagalega/posts/10152770059504300 [22/11/2018].

8. No sentido de proteger o mirandês, em 2017, o Comité de Especialistas para as Línguas Minoritárias (CELM), da Comissão Europeia, recomendou que Portugal assinasse a Carta Europeia de Línguas Minoritárias.

9. Por "planificação linguística" entende-se aqui "all conscious efforts that aim at changing the linguistic behaviour of a speech community" (Mesthrie et al. 2009: 371). 
distinção de qualquer tipo (social, política, étnica, demográfica, tipológica, regional ou nacional, maioritária ou minoritária, antiga ou moderna).

Na campanha intitulada "Language Diversity"10, a União Europeia oferece dados interessantes que dão respaldo ao pessimismo destas reflexóes sobre o futuro do barranquenho (Navas 2014), se este não for objeto de uma intervenção concertada entre os políticos, a comunidade e os investigadores ${ }^{11}$. O barranquenho encontra-se, de facto, em risco pelo número de falantes, pois, como é sabido, segundo dados da UNESCO, qualquer língua falada por menos de 5000 pessoas está ameaçada, e, se se atentar na estatística proporcionada pela Câmara Municipal, em 1985 Barrancos tinha cerca de 4000 habitantes, em 2014 já eram apenas 1754, decréscimo resultante quer do envelhecimento - um quarto da populaçáo tinha, em 2012, mais de 65 anos, segundo dados do Instituto Nacional de Estatística (INE) - quer da procura de emprego fora da comunidade (Correia 2019). Por outro lado, no que diz respeito à vitalidade da língua, de acordo com a opinião dos inquiridos por V. Correia (2019), $65.4 \%$ declaram que atualmente é menos falado do que antes.

Nestas condições, como poderá resistir uma língua ágrafa com o referido número de falantes e uma alta taxa de envelhecimento? O isolamento físico e o apego identitário que têm mantido viva a fala de Barrancos serão suficientes para que não seja assimilada pelo português em poucas geraçôes? Para ser salvaguardado, o barranquenho deverá entrar num novo ciclo da sua história: a chamada normalização ou estandardizaçáo (Metzeltin 2005). É verdade que este é um processo "artificial", já que o processo natural, com tudo quanto ele acarreta - documentação linguística, código escrito, definição de um padrão gramatical e inventário do repertório lexical - costuma produzir-se ao longo séculos, à medida que a comunidade elabora a sua tradiçáo escrita, literária e metalinguística; porém, é necessário para sustentar a memória da língua barranquenha e para atenuar o risco de extinção. Este é, sem dúvida, um caminho que a comunidade de Barrancos terá de percorrer se quiser assegurar a sua identidade barranquenha e criar as melhores condiçóes para a transmissáo intergeracional (Jones 2013: 5) que ainda se verifica atualmente. Sem esta, a língua acabará por dissolver-se irremediavelmente no português, desaparecendo, assim, um património oral de inestimável valor não só para a identidade cultural da comunidade como também para a história do contacto entre as duas línguas românicas (portuguesa e espanhola) em contexto peninsular e europeu, porquanto o caso do barranquenho encontra apenas paralelo, ressalvadas as diferenças, em situaçóes de contacto entre o português brasileiro e o espanhol americano ${ }^{12}$ (Elizaincín 1992; Carvalho 2009). Por isso mesmo, urge documentar o barranquenho.

10. http://language-diversity.eu/en/about-us/who-we-are/ [22/11/2018].

11. Com menos de 300000 falantes, qualquer língua ou variedade está ameaçada.

12. Não se trata aqui de comparar situaçôes linguísticas cujas características são muito diversas; procura-se apenas mostrar a singularidade do barranquenho, como resultado do contacto entre português e espanhol em contexto peninsular e europeu. 


\section{A consciência linguística: a autoestima}

Entre os problemas inerentes à normalização (Navas 2015a) conta-se o desenvolvimento de uma consciência linguística no seio da comunidade. É verdade que a populaçáo barranquenha sempre se sentiu, desde que existe registo disso, diferente dos seus vizinhos, nem espanhola nem portuguesa, consciente de falar algo diferente ${ }^{13}$, como mostra um depoimento recolhido na vila por Victor Adragão (gravação inédita cedida às autoras):

Nós aqui falamos de várias maneras. Por exemplo, de 'a farinha' dizemos [a fa'rina] quando falamos português; [a a'rina] quando falamos barranquenho; e [la ha'rina] quando falamos espanhol.

A atitude dos falantes a respeito da sua própria língua pode conhecer-se com mais detalhe graças a duas incursóes, sob a forma de inquérito, feitas em Barrancos: uma, em 1990, por Navas (2015a) e outra, em 2014, por V. Correia (2019). Na primeira, avaliava-se o nível de prestígio, o hipotético preconceito ou a possível lealdade para cada uma das três línguas faladas na comunidade: o espanhol, o português e o barranquenho. Em termos absolutos, comparativamente com o espanhol, o barranquenho era a língua menos bem avaliada em cinco dos sete itens inquiridos: "bonito" (48,84\%) / (62,79\%), "agradável” (32,56\%) / (46,51\%), "alegre” (46,51\%) / (76,74\%), "fácil" (23,26\%) / (34,88\%) e "vantajoso" (25,8\%) / 34,88\%). Em $62,79 \%$ dos casos, as respostas indicam, inclusivamente, que tanto o português como o espanhol são mais "bonitos" que o barranquenho.

No segundo inquérito, foram entrevistados 52 barranquenhos sobre a sua língua materna, tendo $51,9 \%$ respondido que esta é português com características antigas, e apenas $32,7 \%$ diziam tratar-se de uma língua diferente do português. No entanto, entre os entrevistados por V. Correia (2017) aparentemente o nível de autoestima era muito elevado, já que $80,8 \%$ responderam que gostam de mostrar aos que vêm de fora como se fala a sua língua materna. No que diz respeito à adoção de um sistema gráfico para o barranquenho, o inquérito de V. Correia demonstrou que os entrevistados atribuem importância à criação de uma convenção ortográfica para o barranquenho, porquanto $65,4 \%$ responderam afirmativamente, se bem que esta norma fosse associada sobretudo a textos de registo pouco formal, já que apenas 3,8\% consideraram que fosse útil para traduzir autores consagrados. No mesmo sentido ainda, quando questionados sobre a possibilidade de o barranquenho receber uma proteção oficial equivalente à do mirandês, $86.5 \%$ dos inquiridos manifestaram-se plenamente favoráveis.

13. Veja-se, por exemplo, o programa espanhol "De pueblo en pueblo", que o Canal Extremadura gravou em Barrancos: http://www.canalextremadura.es/alacarta/tv/videos/de-pueblo-en-pueblo-170915 [05/02/2018]. 
Para lá da avaliação feita pela própria comunidade, também os forasteiros se manifestaram, noutros tempos, mas também nos dias de hoje, a respeito da realidade linguística barranquenha, ainda que nem sempre de maneira equânime ou neutra:

Têm um falar que ninguém entende: falam espanhol e quando lá vão portugueses cerram ainda mais o espanhol, de modo a ninguém os entender (depoimento recolhido em Monsaraz e em Mourão, segundo Bastos e Everard 1982: 14).

Eles falam, eles dizem, o que prova a individualidade linguística e cultural da comunidade barranquenha, relativamente até às zonas mais próximas (comentários de uma senhora de Santo Aleixo, recolhidos por V. Correia em 2013, em conversação privada).

Conquanto estas avaliaçóes linguísticas sobre o barranquenho ponham em relevo a sua diferença face ao português, assinalada tanto pelos falantes como pelos forasteiros, o problema da baixa autoestima surge quando os comentários negativos provêm dos próprios barranquenhos:

Ai, mãe, ainda digo que você fala mal! (uma jovem para a sua mãe nascida e criada em Barrancos) (Correia 2017).

Senhora X, que mal que fala! Parece que nem é portuguesa! (compatriota no estrangeiro) (Correia 2017).

Estes testemunhos mostram que alguns falantes tendem a "auto-discriminar" (Ferreira 2017) ou "menorizar" a sua fala local. Porém, importa reconhecer que é difícil manter a autoestima de uma língua quando se constata que os poderes fácticos se expressam em português e os professores discriminam ou, inclusive, encaram de forma negativa, senão mesmo depreciativa, a língua materna - "O que é isso que vocês falam?", "Vejam lá se falam como gente" (dito por um docente na escola de Barrancos, Correia 2019) -, e que, durante muitos anos, era espanhol o único sinal de televisão que ali chegava. Por um lado, houve entre os barranquenhos a pressão do prestígio da língua veicular e, por outro, a forte presença dos meios de comunicação, a imagem, em língua castelhana.

Apesar de a autoestima apresentar fragilidades e favorecer o processo de retrocesso e perda, a defesa das tradiçóes está arraigada em Barrancos (Bastos 1998). O assunto da defesa das corridas de touros à maneira antiga, quer dizer, com a morte do animal na praça a máos do toureiro (Tuleski 2001), parece ter sido um motivo aglutinador dos barranquenhos em torno dos seus costumes. É o que confirma L. Capucha (1994-1995), em Mediterrâneo:

[em Barrancos] os jogos de toiros têm uma importância [...] que transcende de longe os dias de festas, constituindo um elemento central do universo simbólico local, tanto mais quanto a singularidade dos rituais taurinos the confere uma distintividade no plano 
nacional que compensa, pela inversão, a marginalização económica e social a que toda a região - uma das mais pobres e vulneráveis de Portugal - está, cada vez mais, sujeita (apud Franco 2005: 223).

Norberto Franco (2005: 201-449) fez um estudo pormenorizado, já referido, das diversas fases pelas quais passou o problema da corrida de touros em Barrancos e o resultado final com as consequências posteriores de visibilidade e originalidade de Barrancos e seus habitantes, que chegaram a ameaçar com tornarem-se espanhóis: "Acabar com isto? Era a forma de nos tornarmos espanhóis" (Franco 2005: 225). Se os barranquenhos, até esse momento, acreditavam que esta festa tinha razão de ser em nome da tradição descobriram duas coisas: que a proibição era a sério e que tinham sido insultados, injustamente tratados, injuriados na sua pretensão a respeito dos touros, pois era uma "terra rebelde e ingovernável, avessa à lei do Estado" (Franco 2005: 295-296; 244). Este facto terá aglutinado todos os barranquenhos de forma decidida e produziu, além disso, uma "onda de solidariedade" (Franco 2005: 383) entre as povoaçóes próximas, inclusive espanholas, que deram o seu apoio material à deslocação a Lisboa. Para a verbalização da defesa das suas tradiçóes, valores e direitos foi inventada uma escrita que refletisse em cartazes, camisolas e outros meios, alguns slogans sobre a sua especificidade, o que motivou os barranquenhos para um processo de "gramatização" da língua (vale dizer, a transição do código oral para um código escrito), de molde a permitir fazer a transferência do pensamento para a forma grafada, num intento de "convenção ortográfica". Assim despontou uma consciência linguística que, pela primeira vez, se afirmava por meio da palavra escrita, antes reservada ao português e ao espanhol.

\section{Preservação linguística de uma língua ameaçada}

Entre os graves problemas que se colocam para uma avaliação positiva dos barranquenhos face à sua língua conta-se o estatuto que tradicionalmente se atribuiu a esta língua materna, repetidas vezes denominada "dialeto", tanto em textos científicos, em documentos municipais, na imprensa, na rádio e na televisão, como em enunciados de projetos internacionais. Só a partir do Congresso Internacional que se realizou em Barrancos em junho de 2017, e do qual se falará a seguir, a própria comunidade tomou consciência de que a sua fala é uma língua com o mesmo interesse, senão a mesma dimensão, de qualquer das chamadas línguas de prestígio. A partir desse momento, os falantes assimilaram que estavam perante uma língua - a sua -, aceite e reconhecida pela comunidade de especialistas. Teráo, talvez, pensado: se isto que falamos interessa aos especialistas, talvez tenha valor. 


\subsection{Um pouco de história}

Nos finais da década de noventa veio à tona o sentimento da coletividade barranquenha, consciencializada para a defesa das suas particularidades, e foram surgindo algumas iniciativas para a preservação da sua idiossincrasia. Nesta altura, os investigadores do Centro de Linguística da Universidade de Lisboa (CLUL), já haviam completado o Questionário para o Atlas Linguístico e Etnográfico de Portugal e da Galiza (Brissos 2017), alguns investigadores já tinham dado à estampa os seus trabalhos sobre a língua e cultura barranquenhas (Navas 1992), que serviram de ponto de partida de outros, posteriores, e a própria Câmara Municipal de Barrancos tinha ido editando volumes que tratavam de vários assuntos, entre eles, geologia (Piçarra et al. 2001) ou história local (Coelho 1986).

Em 1999, a Câmara criou o Grupo de Estudo do Barranquenho (G.E.B.); em 2002 teve lugar a reuniáo inaugural do Mubimêntu du Pobu Barranquenhu di Barrancû en Purtugá (MPB)14 "[...] para não se perder para sempre este legado cultural, que é o idioma Barranquenho"; três anos depois, em 2005, há notícia da correspondência entre a Divisão de Ação Social-Cultural do Munícipio de Barrancos e alguns especialistas para se pôr em marcha outro projeto: Estudo do barranquenho.

O primeiro reconhecimento do estatuto de língua deve partir da própria comunidade e, nesse sentido, no dia 24 de junho de 2008 a Câmara classificou, como já se disse, o barranquenho como Património Cultural Imaterial de Interesse Municipal. Esta medida política, que teve como objetivo elevar a autoestima da comunidade e sensibilizá-la para a preservação da sua tradição oral, desenvolveu-se na sequência da realização a 22 de fevereiro de 2008, na Universidade de Évora, de uma Jornada de Falares Fronteiriços, cujo programa colocou o foco, precisamente, no barranquenho, contando com a participação dos próprios falantes. Como resultado desse encontro, foi assinado um protocolo entre aquela Universidade, o Centro de Linguística da Universidade de Lisboa e a Câmara Municipal de Barrancos, constituindo-se, assim, o projeto Património linguistico na raia (Alentejo e Extremadura).

\subsection{Classificar para preservar}

A referida classificação, em 2008, da língua barranquenha como Património Cultural Imaterial representava, contudo, um passo inicial para uma verdadeira "planificação linguística" de médio e longo prazo, de maneira a serem criadas condiçôes internas que náo só fomentassem a consciência linguística e uma atitude positiva dos falantes em relação à sua língua, como também os comprometesse com o processo

14. Veja-se aqui como a comunidade tenta representar graficamente a sua língua. 
de normalizaçáo de maneira a que tudo conduzisse ao reconhecimento no plano nacional.

Em 2009, ao abrigo de um Projeto ${ }^{15}$ promovido pela Associação de Defesa do Património de Mértola, financiado no âmbito do Programa Operacional do Alentejo 2007-2013, foi publicado em suporte digital Do saber ao contar, volume que reúne informação e documentos (fotografias, por exemplo) relativos a assuntos como o contrabando, além de contos, lendas, ofícios tradicionais ou plantas aromáticas e medicinais (Revez \& Cascalheira 2010); por outro lado, a Câmara Municipal de Barrancos, em parceria com entidades externas (Universidade de Évora, Centro de Linguística da Universidade de Lisboa e Universidade Complutense de Madrid), candidatou o projeto Preservação e Valorização do Barranquenho - Um caminho para a sustentabilidade local a um Programa de financiamento regional, tendo em vista obter recursos para estudar e salvaguardar uma das maiores riquezas da comunidade barranquenha. Embora o projeto não tenha chegado à fase de execução, a convençáo ortográfica, por ser objeto de uma tese de doutoramento, seguiu o seu curso e está agora, finalmente, em fase de conclusão. Reestruturado em outros moldes e com o título de Conservação e Valorização do Património Rural, em 2011 o projeto foi objeto de candidatura ao programa 3.2.1 PRODER (Rota do Guadiana), que não foi bem sucedida.

Passados alguns anos, em 2013 (4 de dezembro), realizou-se na Universidade de Évora o I Seminário Internacional História e Lingua: Interfaces, que se centrou, mais uma vez, no caso do barranquenho, iniciativa sem outra continuidade. Seguindo o caminho do impulso e defesa da língua e cultura barranquenhas, em dezembro de 2016, propôs-se à Câmara Municipal de Barrancos a organização conjunta de um Congresso Internacional que promovesse o património imaterial local, reuniáo científica que decorreu em Barrancos a 2 de junho de 2017. Auspiciado pelo Centro Interdisciplinar de História, Culturas e Sociedades da Universidade de Évora e a Cátedra UNESCO em Intangible Heritage and Traditional Know-How: linking heritage, sediada na mesma Universidade, o Centro de Linguística da Universidade de Lisboa, a Universidade Complutense de Madrid, o projeto Frontera hispano-portuguesa: documentación lingüistica y bibliográfica (FRONTESPO) e a Direção Regional de Cultura do Alentejo, o Congresso Internacional $O$ barranquenho: ponte entre linguas e culturas. Passado, presente e futuro, reuniu em Barrancos, pela primeira vez na história em geral e, em particular, na desta comunidade, alguns dos maiores investigadores da língua barranquenha, das línguas de contacto e línguas ameaçadas. Tratava-se de fazer o estado da questáo a respeito dos estudos realizados sobre o Barranquenho, de conhecer o caminho seguido por outra língua cooficial em Portugal - o mirandês - , e por outras línguas que pretendem o mesmo reconhecimento, como é o caso do minderico ${ }^{13}$ (Ferreira \& Bouda 2009). Foram igualmente convidados especialistas de

15. Tradiçôes Orais e Cultura Popular no Baixo Alentejo: Memorias Orais - Aprendizagens Globais. O minderico está registado com o Código ISO 639-3 DRC. 
política linguística e de património intangível com vista a que, futuramente, algumas manifestações da cultura barranquenha, se for essa a decisão da comunidade, venham a ser incluídas na Matriz Nacional de Património Imaterial e, se possível, em outras bases internacionais (Fernández Rei 2014).

$\mathrm{Na}$ sessão de encerramento foram apresentadas as principais linhas de trabalho resultantes do Congresso. Entre os aspetos ali mencionados, salientaram-se os seguintes: a urgência em registar a língua, sob pena de desaparecerem os falantes das geraçôes mais antigas e se romperem os elos intergeracionais, seguindo a metodologia de documentação já aplicada por Vera Ferreira (Centro Interdisciplinar de Documentação Linguística e Social - CIDLeS) ${ }^{16}$ ao caso do minderico, no sentido de dar formação intensiva a membros da comunidade barranquenha que estejam interessados em documentar a sua língua e, ao mesmo tempo, criar um "arquivo local", de forma a ser guardada a memória do barranquenho no seu uso diário; a existência no Centro de Linguística da Universidade de Lisboa de um vasto acervo de gravaçóes de falantes barranquenhos, fruto do trabalho de campo realizado no âmbito do Atlas Linguístico e Etnográfico de Portugal e da Galiza (ALEPG), materiais que permitirão vários tipos de estudo; a necessidade de o barranquenho passar por um processo normalizador e codificador (ortografia, gramática e dicionário) que permita a sua entrada no contexto escolar local (mas não só), possibilitando as melhores condiçôes de preservação, aquisição e estudo; as vantagens de uma planificação de política linguística e patrimonial, concertada entre várias entidades, bem como a necessidade de uma abordagem multidisciplinar que, além de linguistas, inclua especialistas em Património Imaterial (Cátedra da UNESCO da Universidade de Évora) e Antropologia, que possam assessorar uma eventual candidatura à inscrição na Matriz de Património Cultural Imaterial; e, por último, mas não menos importante, a criação de uma comissão para "tutelar", com objetivos de curto, médio e longo prazo, tudo quanto se refira à língua e cultura barranquenhas.

Chamam-se aqui à colação os objetivos e contributos deste congresso, por ser o corolário de iniciativas anteriores e porque a sua realização, em Barrancos e com o envolvimento de falantes de barranquenho (Ferreira 2017) - língua mista, minoritária e ameaçada -, se inscreve claramente no chamado "prestige planning" (Deumert 2009), expressão que, entre os especialistas das áreas da política e planificação linguísticas, denomina o conjunto de medidas e atividades destinadas a desenvolver atitudes positivas (consciência linguística, autoestima) em torno da língua materna (Navas 2015a). Com efeito, a condição do barranquenho como língua ameaçada manifesta-se na menorização e no desprestígio revelados nos inquéritos feitos em Barrancos, pelo que se torna imperiosa a adoção de uma política e uma planificação contínuas de valorização da língua local.

Ora, o referido congresso permitiu precisamente que o poder local e a comunidade de falantes (residentes habituais e emigrados na região de Lisboa) tomassem

16. http://www.cidles.eu/ [08/02/2018]. 
consciência do valor que os especialistas - linguistas e investigadores de outras áreas - reconhecem a esta língua mista, que eles próprios escondiam com muita frequência, talvez por lhe atribuírem um "estatuto inferior" ao do português. Mas o congresso trouxe outras revelaçóes, quer para os especialistas, quer para a comunidade barranquenha: a uns veio mostrar que as crianças, que também intervieram durante uma mesa redonda sobre a "consciência linguística", falam barranquenho pelo menos até irem para a escola; aos outros, mostrou-lhes que a presença de tantas autoridades nacionais e estrangeiras interessadas no barranquenho (ao qual os próprios falantes chamavam "dialeto") só pode significar que esta língua merece ser falada, preservada e reconhecida.

Em linha com as recomendações da União Europeia, preservar o barranquenho é defender uma parte importante da diversidade linguística da Península Ibérica. Trata-se, pois, da promoção de uma língua, reflexo de uma cultura específica numa geografia também muito específica, de uma situação política relativa à igualdade de direitos dos cidadáos da República Portuguesa, política essa em que será preciso abordar as "dinâmicas históricas e emocionais associadas às identidades e subjetividades" (Keating \& Ferreira 2017), de modo a que os barranquenhos, se assim o entenderem, transponham as fronteiras sociais existentes, reapreciem os seus próprios níveis de competência linguística e reestruturem as suas práticas sociais para se adaptarem a novos espaços linguísticos, complexos e sobrepostos. Se, tal como diz Fernando Aramburu (El País 04/03/2018: 32), "la identidad es un necesidad básica del ser humano”, então a salvaguarda da língua barranquenha deve ser tomada como uma exigência capital dos barranquenhos. É, pois, necessário, pôr em andamento políticas de língua, gestão da diversidade, reconhecimento institucional e, por último, ação governamental.

$\mathrm{Na}$ sequência de várias reunióes e encontros ao longo de 2018, promovidos pela Câmara Municipal de Barrancos em conjunto com a Universidade de Évora, a Cátedra da UNESCO, o Centro de Linguística da Universidade de Lisboa e o Centro Indisciplinar de Documentação Linguística e Social (CIDLeS), foi decidido travar o desaparecimento da língua barranquenha e preservar o património barranquenho como um todo, compreendendo e articulando tanto o património material como o património imaterial, numa estratégia de salvaguarda da língua e cultura como factos indissociáveis e, deste modo, fomentar, no seio da comunidade, uma consciência de defesa do que é seu. De acordo com as diretrizes de vários organismos internacionais em matéria de defesa e protecção das línguas minoritárias e ameaçadas, ao amparo da Convenção para a Salvaguarda do Património Cultural Imaterial da UNESCO, aprovada a 17 de outubro de 2003, ratificada pelo Decreto do PR no 28/2008 de 26/3, no seu artigo 2, secção a), entende-se por "património cultural imaterial as práticas, representaçóes e expressóes, conhecimentos e aptidóes [...] que as comunidades, os grupos e, sendo o caso, os indivíduos reconheçam como fazendo parte integrante do seu património cultural”. Assim, a língua pode ser entendida como uma prática an- 
cestral e uma tradição cultural, reflexo da especificidade local, o que está em sintonia com as recomendaçóes que, desde a década de 90 do século passado, já propunham várias organizaçôes que defendiam a consagração universal do valor cultural das línguas, sobretudo as minoritárias ou ameaçadas. Todas estas medidas visam, claro está, a formalização do barranquenho como Património Imaterial Nacional e, posteriormente, como Património Imaterial da Humanidade.

Nesse sentido, é preciso levar para o terreno políticas para a língua e cultura barranquenhas, motivo por que, entre a Câmara Municipal de Barrancos e os organismos anteriormente referidos - Universidade de Évora e a Cátedra da UNES$\mathrm{CO}$, o Centro de Linguística da Universidade de Lisboa e o Centro Indisciplinar de Documentação Linguística e Social (CIDLeS) -, foi assinado um Programa de Preservação e Valorização do Património Cultural Barranquenho, financiado com cerca de 50.000 euros pela mencionada edilidade, tendo em vista levar a cabo, ao longo de três anos (2020-2022) uma série de tarefas, cujos responsáveis científicos são Maria Filomena Gonçalves, María Victoria Navas, Filipe Themudo Barata e Vera Ferreira. No cronograma proposto incluem-se: 1) documentar (linguística e culturalmente) o Barranquenho e, como resultado, criar um arquivo de memória linguística e cultural; 2) desenvolver um Portal web que reúna e disponibilize todas as informaçóes bibliográficas existentes sobre a língua e cultura barranquenhas, assim como outros dados relevantes para a sua investigação; 3) desenvolver vários tipos de actividades (didáticas, lúdicas, formativas, entre outras), na escola, nas associaçóes culturais e outras, visando promover a autoestima da comunidade; 4) preparar, para discussão pública e aprovação, uma Convenção Ortográfica para o Barranquenho, 5) elaborar e publicar uma gramática básica do Barranquenho; 6) elaborar e publicar um dicionário trilingue, barranquenho-português-espanhol; 7) introduzir o barranquenho na escola; 8) realizar o II Congresso Internacional sobre a Língua e Cultura Barranquenhas.

\section{Notas finais}

Os dados aqui aduzidos sobre a situaçáo atual do barranquenho - fruto do contacto entre variedades meridionais de duas línguas românicas (português e castelhano), minoritária (com menos de 1800 falantes) e ameaçada (depressão demográfica, fraca autoestima, desprestígio face ao português, a língua estândar, da escolarizaçáo e dos media, inexistência de emprego na comunidade) - tiveram como objetivo mostrar, por um lado, os vários passos que, ao longo do tempo, têm sido dados com vista à defesa da língua e cultura de Barrancos e, por outro, as reaçóes da comunidade perante a invasão dos seus direitos, e nas quais têm revelado uma defesa férrea das suas tradiçóes culturais. O firme interesse mostrado pela Câmara Municipal de Barrancos, em representação dos seus munícipes, na adoção e no financiamento de medidas de 
política linguística, agora plasmadas no Programa de Preservação e Valorização do Património Cultural Barranquenho, constitui um passo decisivo no sentido de se manter a especificidade única da língua e cultura barranquenhas.

\section{Financiamento}

Trabalho realizado no âmbito dos projetos 'Frontera hispano-portuguesa: personas, pueblos y palabras' (Frontespo-3P), financiado pelo FEDER/Ministerio de Ciencia, Innovación y Universidades-Agencia Estatal de Innovación, periodo 2019-2022, ref. RTI2018-095899-B-I0 e CIDEHUS.UE/FCT-UIDB/00057/2020. 


\section{Referências bibliográficas}

Adragáo, José Victor. 1978. Rapports locuteur-côde: un cas de choix libre? Em Alberto Varvaro (ed.), Atti XIV Congresso Internazionale di Linguistica e Filologia Romanza, vol. II. 565-575. Napoli / Amsterdam: Gaetano Macchiaroli / John Benjamins. https://doi.org/10.1075/z.9.ii44rap

Alvar, Manuel. 1996. Barranqueño. Em Manuel Alvar (ed.), Manual de dialectología hispánica. El español de España. 259-262. Barcelona: Ariel.

Aramburu, Fernando. 2018. La identidad es una necesidad básica del ser humano. El País, 32. (04/03/2018).

Bakker, Peter. 2015. Typology of mixed languages. Em Alexandra Yurievna Aikhenvald \& Robert Malcom Ward Dixon (eds.), The Cambridge handbook of linguistic typology. 217-253. Cambridge: Cambridge University Press. https://doi.org/10.1017/9781316135716.008

Bastos, Cristiana Lage David \& Pedro Duarte Alves de Lara Everard. 1982. Da antropologia ao antropólogo: Barrancos de um percurso. Lisboa: Universidade Nova de Lisboa. (Texto inédito).

Bastos, Cristiana. 1998. (In)visible borders: ideologies of sameness and otherness in a Portuguese context. Portuguese Literary \& Cultural Studies. Fronteiras/Borders 1, 19-32.

Brissos, Fernando. 2017. Materiais relativos ao barranquenho recolhidos para o Atlas Linguístico de Portugal e da Galiza. Em Congresso Internacional O barranquenho, ponte entre linguas e culturas. Passado, presente e futuro. Barrancos, 2 de Junho de 2017. (Comunicação inédita).

Capucha, Luís Manuel A. 1994-1995. O espelho quebrado: versus e reversus nas tauromaquias populares. Mediterrâneo 5-6, 33-57.

Carvalho, Ana Maria (ed.). 2009. Português em contato. Linguística Luso-Brasileira 2. Frankfurt am Main: Vervuert Verlag. https://doi.org/10.31819/9783964563002

Carvalho, Ana Maria \& Dante Lucchesi. 2016. Portuguese in contact. Em Willem Leo Wetzels, Sergio Menuzzi \& João Costa (eds.), The Handbook of Portuguese Linguistics. 41-55. Malden / Oxford: Wiley Blackwell. https://doi.org/10.1002/9781118791844.ch3

Clements, Joseph Clancy. 2009. Barranquenho. Em The Linguistic Legacy of Spanish and Portuguese: Colonial expansion and language change. 190-209. Cambridge: Cambridge University Press. https://doi.org/10.1017/CBO9780511576171.009

Clements, Joseph Clancy, Patrícia Amaral \& Ana Luís. 2007. El barranqueño: una lengua de contacto en Iberia. Estudios Portugueses: Revista de Filologia Portuguesa 7, 37-46.

Clements, Joseph Clancy, Patrícia Amaral \& Ana Luís. 2008. Cultural identity and the structure of a mixed language: The case of Barranquenho. Em Proceedings of the Annual Meeting of the Berkeley Linguistics Society (BLS) 34, Special session on Pidgins, Creoles, and Mixed Languages. http:// linguistics.berkeley.edu/bls/previous_proceedings/bls34.pdf (14/03/2018).

Clements, Joseph Clancy, Patrícia Amaral \& Ana Luís. 2011. Spanish in contact with Portuguese: The case of Barranquenho. Em Manuel Díaz-Campos (ed.), The Handbook of Hispanic Sociolinguistics. 395-417. Oxford: Blackwell Handbooks in Linguistics. https://doi. org/10.1002/9781444393446.ch19 (16/03/2019).

Coelho, Adelino de Matos. 1986. O Castelo de Noudar fortaleza medieval. Lisboa: Câmara Municipal de Barrancos. 
Correia, Victor Manuel Diogo. 2017. O barranquenho: vantagens de uma convenção ortográfica. Em Congresso Internacional - O barranquenho: ponte entre linguas e culturas. Passado presente e futuro. Barrancos, 2 de Junho de 2017. (Comunicação inédita).

Correia, Victor Manuel Diogo. 2019. O barranquenho: urgência de uma política linguística? Revista de Filología Románica 36, 169-178. https://doi.org/10.5209/RFRM.63511

Cosme, João. 2001. Fontes para a história de Barrancos. Registos paroquiais (1674-1704). Barrancos: Câmara Municipal de Barrancos.

Decreto n. ${ }^{\circ}$ 303/VII - Reconhecimento oficial de direitos linguisticos da comunidade mirandesa, II Série - n. ${ }^{\circ}$ 29,786.http://debates.parlamento.pt/catalogo/r3/dar/s2a/07/04/028/1999-01-09/786?pgs=786 \&org=PLC (12/02/2018).

De pueblo en pueblo. Canal Extremadura. http://www.canalextremadura.es/alacarta/tv/videos/de-pueblo-en-pueblo-170915 (05/02/2018).

Deumert, Andrea. 2009. Language planning and policy. Em Rajend Mesthrie, Joan Swann, Ana Deumert \& William L. Leap (ed.), Introducing Sociolinguistics. 2. ${ }^{a}$ edn. 384-418. Amsterdam / Edinburgh: John Benjamins / Edinburgh University Press.

Elizaincín, Adolfo. 1992. Dialectos en contacto: español y portugués en España y América. Montevideo: Arca.

European Charter for Regional and Minority Languages, Série des traités européens, n. ${ }^{\circ}$ 148, Strasbourg, 5.11.1992 (publicada em versão espanhola oficial como Carta europea de las lenguas regionales y minoritarias, em Boletín Oficial del Estado, 5 de setembro 2001). https://www.boe.es/boe/ dias/2001/09/15/pdfs/A34733-34749.pdf (12/02/2018).

Fernández Rei, Francisco. 2014. O barranqueño terceira lingua oficial de Portugal? ProLingua. https:// www.facebook.com/Prolinguagalega/posts/10152770059504300 (22/11/2018).

Ferreira, Manuela Barros \& Domingos Raposo (coords.). 1999. Convenção ortográfica da língua mirandesa. Miranda do Douro / Lisboa: Câmara Municipal de Miranda do Douro / Centro de Linguística da Universidade de Lisboa.

Ferreira, Vera. 2017. Da auto-discriminação à revitalização: a importância da documentação e envolvimento comunitário no processo de revitalização do minderico. Em Congresso Internacional $O$ barranquenho, ponte entre linguas e culturas. Passado, presente e futuro. Barrancos, 2 de Junho de 2017. (Comunicação inédita).

Ferreira, Vera \& Peter Bouda. 2009. Minderico: an endangered language in Portugal. Em Peter Kenneth Austin, Oliver Bond, Monik Charette, David Nathan \& Peter Sells (eds.), Proceedings of Conference on Language Documentation and Linguistic Theory 2. 95-106. London: SOAS.

Ferreira, Vera, Peter Bouda, Paulo Carvalho Vicente \& Ilona Schulze. 2015. Dicionário bilingue. Piação-Português. Fátima: Centro Interdisciplinar de Documentação Linguística e Social (CIDLeS).

Franco, Norberto. 2005. O porquê de Barrancos. A cultura, a história, os touros, o direito. 2a edn. Barrancos: Município de Barrancos.

Golovko, E. V. 2003. Language contact and group identity: The role of 'folk' linguistic engineering. Em Yaron Matras \& Peter Bakker (eds.), The mixed language debate: Theoretical and empirical advances). 177-208. Berlin: Mouton de Gruyter.

Jones, Meirion Prys. 2013. As línguas ameaçadas de extinção e a diversidade linguística na União Europeia. Parlamento Europeu: Direcção-Geral das Políticas Interiores / Departamento Temático B (Políticas estruturais e de coesão). http://www.europarl.europa.eu/studies (12/06/2018). 
Keating, Clara \& Vera Ferreira. 2017. Multilingualism and linguistic diversity in Portugal: Speakers, Knowledge and Dynamics. Em The New Speakers Network. Final Action Conference. Coimbra: Faculdade de Letras da Universidade de Coimbra. (Conferência inédita).

Lagares, Xoán Carlos. 2018. Qual politica linguistica? Desafios glotopolíticos contemporâneos. São Paulo: Parábola.

Language diversity. Uniāo Europeia. http://language-diversity.eu/en/about-us/who-we-are/ (18/02/2018).

Matras, Yaron \& Peter Bakker (eds.). 2003. The mixed language debate: Theoretical and empirical advances. Trends in Linguistics. Studies and Monographs 145. Berlin: Mouton de Gruyter. https:// doi.org/10.1515/9783110197242

Meakens, Felicity. 2018. Mixed languages. Em Paula Rabinowitz (ed.), Oxford Research Enciclopedias: Literature. 1-29. Oxford: Oxford University Press. https://doi.org/10.1093/acrefore/9780199384655.013.151

Mesthrie, Rajend, Joan Swann, Ana Deumert \& William L. Leap. 2009. Introducing Sociolinguistics. Amsterdam / Edinburgh: John Benjamins / Edinburgh University Press.

Metzeltin, Miguel. 2005. Las lenguas románicas estándar. Historia de su formación y de su uso. Uviéu: Academia de la Llingua Asturiana / Llibrería Lingüística.

Metzeltin, Michael. 2015. Las lenguas: sistemas inestables pero necesarios. Luenga \& Fabla 19, 9-18.

Navas Sánchez-Élez, María Victoria. 1992. El barranqueńo: un modelo de lenguas en contacto. Revista de Filología Románica 9, 225-246.

Navas Sánchez-Élez, María Victoria. 2000. Procesos de creación de lenguas fronterizas. Revista de Filología Románica 17, 367-393.

Navas Sánchez-Élez, María Victoria. 2011. El barranqueño. Un modelo de lenguas en contacto. Madrid: Editorial Complutense / Centro de Linguística da Universidade de Lisboa.

Navas, María Victoria Sánchez-Élez. 2013. Mujeres depositarias y transmisoras de un patrimonio intrafronterizo: el ejemplo de la villa portuguesa de Barrancos. Em Margarita Almela, María García Lorenzo, Helena Guzmán \& Marina Sanfilipo (coords.), Mujeres en la frontera. 153-170. Madrid: UNED.

Navas, María Victoria Sánchez-Élez. 2014. Presente, pasado y futuro de una lengua de contacto lusoespañola. Em José María Santos Rovira (ed.), Fronteras y diálogos del español y otras lenguas. 89-100. Lisboa: Axac.

Navas Sánchez-Élez, María Victoria. 2015a. Actitudes lingüísticas en una situación de contacto de lenguas. Revista de Filología Románica 32, no1, 11-20. https://doi.org/10.5209/RFRM.54689

Navas Sánchez-Élez, María Victoria. 2015b. El barranqueño, lengua oral versus lengua estándar: estado de la cuestión. Luenga \& Fabla 19, 83-89.

Navas Sánchez-Élez, María Victoria. 2017a. O barranquenho: Lingua, Cultura e Tradição. Lisboa: Ediçōes Colibri.

Navas Sánchez-Élez, María Victoria. 2017b. Reparto de papeles en la transmisión oral desde el punto de vista del género. Em Marina Sanfilipo, Helena Guzmán \& Ana Zamorano (coords.), Mujeres de palabra. Género y narración oral en voz femenina. 63-69. Madrid: UNED.

Navas Sánchez-Élez, María Victoria. 2017c. Intercambios culturales y lingüísticos en la raya hispanoportuguesa: estado de la cuestión. Em Dolores Corbella \& Alejandro Fajardo (eds.), Español y portugués en contacto: préstamos léxicos e interferencias, Número monográfico de Zeits- 
chrift für romanische Philologie (BZrP) 419. 79-104. Berlin / Boston: De Gruyter. https://doi. org/10.1515/9783110552027

Navas Sánchez-Élez, María Victoria \& Maria Filomena Gonçalves. 2018. La codificación de una lengua oral: problemas e hipótesis. Em Roberto Antonelli, Martin Glessgen \& Paul Videsott (eds.), Atti del XXVIII Congresso Internazionale di Linguistica e Filologia Romanze, Vol. II. 1427-1438. Strasbourg: ELiPHi - Éditions de Linguistique et Philologie.

Piçarra, José Manuel, Zelia Pereira, V. Oliveira \& José Tomás Oliveira. 2001. Breves apontamentos sobre a geologia da regiāo de Barrancos. Barrancos: Câmara Municipal de Barrancos.

Quijada Coronel, Beatriz. 2012. Patrimonio cultural en la frontera Alentejo-Extremadura. Las nanas, ¿una tradición oral viva? Universidade de Évora. Dissertação de Mestrado inédita.

Revez, Jorge \& Sandra Cascalheira (coords.). 2010. Do saber ao contar. Memórias das tradiçöes e oficios dos concelhos de Almodôvar, Barrancos e Mértola. Mértola: Associação de Defesa do Património de Mértola.

UNESCO. 1996. Declaración universal de los derechos lingüísticos. Em Conferencia mundial de derechos lingüisticos. Barcelona, 6 a 9 de junho de 1996. http://www.unesco.org/cpp/sp/declaraciones/linguisticos.htm (11/03/2018).

UNESCO. 2003. Convençāo para a Salvaguarda do Património Cultural Imaterial. http://www.unesco. org/culture/ich/es/convenci\%C3\%B3n (11/03/2018).

Tuleski, Valéria Eneida Ruviaro. 2001. 'Touros de morte' em Barrancos: uma tradição da fronteira luso-espanhola. Lisboa: Instituto Superior de Ciências do Trabalho e da Empresa. (Dissertação de Mestrado inédita).

Vasconcelos, José Leite de. 1897. Mappa Dialectologico do Continente Português. Lisboa: Guillard, Aillaud \& Cia.

Vasconcelos, José Leite de. 1935. Linguagens fronteiriças. Revista Lusitana 33 (1-4), 307-309.

Vasconcelos, José Leite de. 1939. Da fala de Barrancos. Boletim de Filologia 6, 159-177.

Vasconcelos, José Leite de. 1955. Filologia barranquenha. Apontamentos para o seu estudo. Lisboa: Imprensa Nacional de Lisboa (reed. facsimilada, 1981).

Vasconcelos, José Leite de. 1987. Note sur le parler de Barrancos, em Esquisse d'une dialectologie portugaise. 125-128. Lisboa: INIC / Centro de Linguística da Universidade de Lisboa. (Primeira edición de 1901). 